\title{
A Novel Design of Wave-Like PEMFC Stack with Undulate MEAs and Perforated Bipolar Plates
}

\author{
P. Y. Yi ${ }^{1}$, L. F. Peng ${ }^{1}$, X. M. Lai ${ }^{1 *}$, D. A. Liu' ${ }^{1}$, and J. $\mathrm{Ni}^{2}$ \\ 1 State Key Laboratory of Mechanical System and Vibration, Shanghai Jiao Tong University, Shanghai 200240, People's Republic of \\ China \\ 2 Department of Mechanical Engineering, University of Michigan, Ann Arbor, Ml 48109-2125, USA
}

Received February 20, 2009; accepted December 11, 2009

\section{Abstract}

Commercialisation of proton exchange membrane fuel cell (PEMFC) technology depends on high volumetric power density and specific power for a given cost. In the present study, a novel wave-like architecture for PEMFC stack based on undulate membrane electrode assembles (MEAs) and perforated bipolar plates (PBPs) was presented. Different from conventional plate-and-frame architecture, this design increased active area and achieved higher volumetric power density due to undulate MEAs. Moreover, perforated sheet metal was used as bipolar plates so that it could improve specific power.

A single cell was designed and fabricated in house to evaluate the performance of the novel architecture stack.
Stamped PBPs with open rate of $28.26 \%$ and hot pressed 5-layer undulate MEAs with Nafion ${ }^{\circledR} 112$ were adopted. The results indicated that the peak volumetric power density and specific power are $2,715.94 \mathrm{~W} \mathrm{~L}^{-1}$ and $2,157.86 \mathrm{~W} \mathrm{~kg}^{-1}$, respectively, while they are $2,151.28 \mathrm{~W} \mathrm{~L}^{-1}$ and $1,709.22 \mathrm{~W} \mathrm{~kg}^{-1}$ at the output voltage of $0.6 \mathrm{~V}$. This study may propose a possible means to meet the DOE's 2010 technical target that volumetric power density is $2,000 \mathrm{~W} \mathrm{~L}^{-1}$ and specific power is $2,000 \mathrm{~W} \mathrm{~kg}^{-1}$ for stack.

Keywords: PEM Fuel Cell, Perforated Bipolar Plate, Specific Power, Undulate MEAs, Volumetric Power Density

\section{Introduction}

Fuel cells are being pursued for a wide variety of applications due to their high theoretical efficiency and environmental friendliness $[1,2]$. In particular, proton exchange membrane fuel cells (PEMFCs), because of the advantages of low temperature operation, fast start-up, system robustness and low emissions, are attractive for automotive and portable applications [3]. However, commercialisation of PEMFC technology depends on achieving high volumetric power density and specific power for a given cost, so that its characteristics compete cost-effectively with traditionally used energy conversion devices [4]. The US Department of Energy's (DOE) 2010 technical target for automotive fuel cell power systems operating on direct hydrogen is that volumetric power density is $2,000 \mathrm{~W} \mathrm{~L}^{-1}$ and specific power is $2,000 \mathrm{~W} \mathrm{~kg}^{-1}$ for stack [5]. Optimisation the stack architecture and usage of low-cost lightweight material for bipolar plates are two effi- cient ways to improve the fuel cell power density and lower its cost simultaneously.

As shown in Figure 1, conventional PEMFC stack designs have been based on planar, repetitively stacked structure that use milled or pressure-moulded plates to deliver fuel and oxidant gases to the reaction sites. Nevertheless, some new structural designs for PEMFCs have been proposed for higher power density by modifying the geometries of membrane electrode assembles (MEAs) or bipolar plates in recent years. A micro-tubular fuel cell was developed by NASA to improve the volumetric power density for portable electronic equipments [6]. The MEAs were tubular in shape which could be packed into a small case with oxygen/hydrogen cross flow. This design increased the power density because

[*] Corresponding author, xmlai@sjtu.edu.cn 


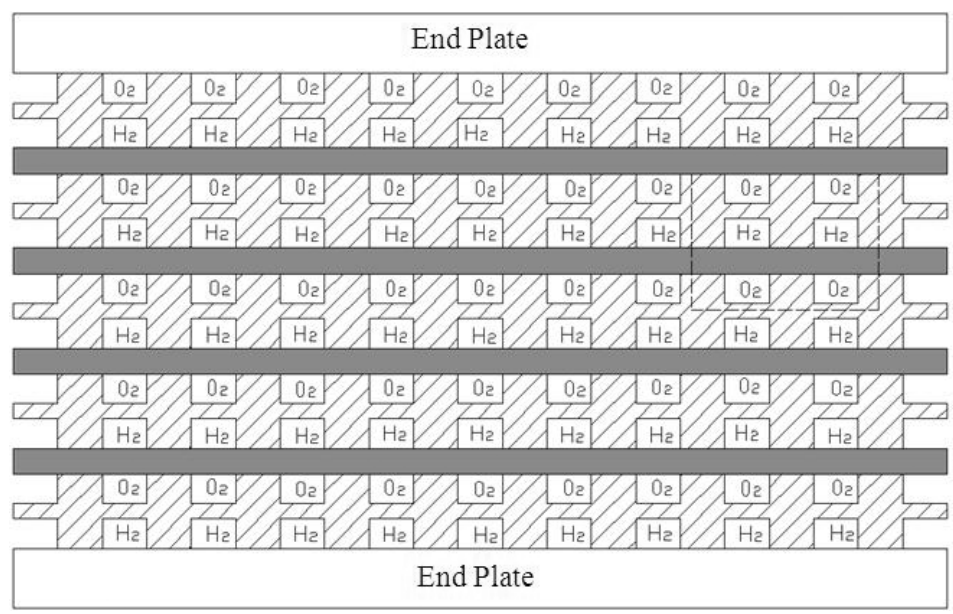

Fig. 1 Schematic of conventional plate-and-frame architecture PEMFC stack.

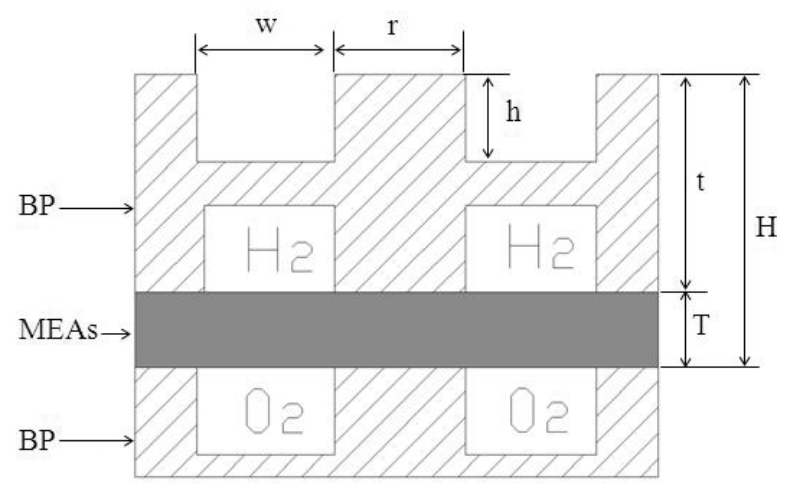

the elimination of the bipolar plates and the tubular design of MEAs greatly utilised the available volume of the fuel cell. Merida et al. [7] put forward a non-planar architecture for PEMFCs and developed two prototypes to evaluate the cell performance. The testing results showed that the non-planar MEA obtained about 1.5 times the volumetric power density of the planar MEA at the peak power density level. Nikam and Reddy [8] introduced a method to use corrugated bipolar sheets as fuel distributors. A single cell which was observed to save $\sim 11 \%$ on weight and $55 \%$ on cost, respectively, showed better performance than the conventional one. The effects of buoyancy on the performance of a PEMFC with a wave-like gas flow channel design were investigated by Kuo and Chen $[9,10]$ with numerical method. The simulation results showed that the wave-like gas flow channel increased the output voltage and improved the maximum power density by $\sim 39.5 \%$.

Traditionally, graphite and graphite composite plates with machined flow fields have been widely used in PEMFC because of their high corrosion resistance, and low interfacial contact resistance (ICR). However, their poor manufacturability results in high manufacturing cost, and their brittleness
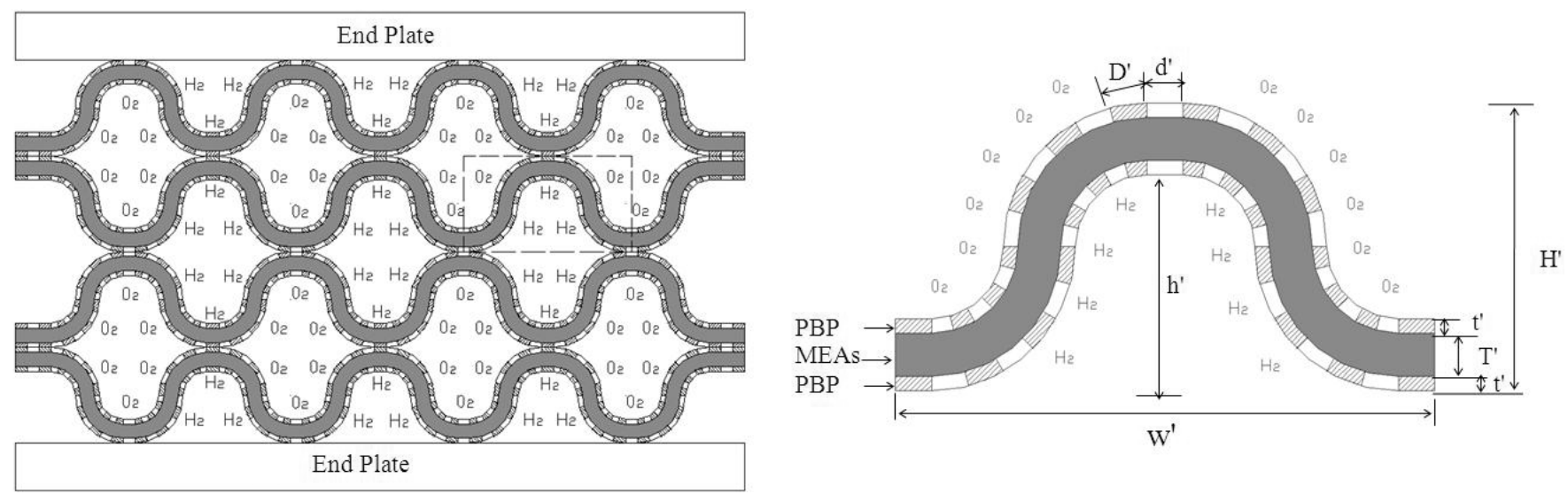

Fig. 2 Schematic of novel wave-like architecture PEMFC stack. requires the use of fairly thick plates for adequate mechanical strength [11]. Recently, metallic bipolar plates, such as aluminium, stainless steel, nickel, titanium, etc., have received much attention as alternative materials for bipolar plate because of their superior mechanical strength, low gas impermeability, very high bulk electrical and thermal conductivity, relatively low material and fabrication cost [12]. In particular, with the achievements of suitable coatings [11, 13, 14], stainless steel is considered to be the most widely used candidate for metallic bipolar plates $[15,16]$.

In the present study, a novel wave-like architecture for PEMFC was proposed to improve the volumetric power density and specific power. The novel wave-like architecture PEMFC stack is mainly composed of undulate MEAs and perforated bipolar plate (PBP), as illustrated in Figure 2. Two wave-like bipolar plates hold undulate MEAs. The cavities between two bipolar plates work as flow channels so that the hydrogen and oxygen in these channels can pass though the PBPs and reach the catalyst layers of MEAs by the action of GDL. Theoretically, the design of novel wave-like architecture can provide intrinsically higher volumetric density and specific power for three factors: active area is increased under 
certain projected area and cell height due to undulate MEAs; the height of each cell is reduced under the same depth of flow channel because each channel is shared by two adjacent cells and convexes of one bipolar plate are inserted into concaves of the other one; high density of stainless steel can be mitigated by using thin and perforated sheets. As a result, perforated thin sheet metal bipolar plate is lighter than the conventional bipolar plate though the density of stainless steel is almost four times of graphite. Besides, this novel design has the potential for significantly improved manufacturability and reduced cost because the perforated sheet metal bipolar can be manufactured by the stamping process.

\section{Experimental}

Stamping process, which is low cost and suitable for mass production, was adopted for PBP fabrication. According to the characters of this process, the flow channels on both sides of wave-like bipolar plate are different: while one side of stamped bipolar plate is interdigitated flow field, the other side is serpentine flow field. Considering the utilisation of fuel $[17,18]$, interdigitated flow field was used for hydrogen channel in anode while serpentine flow field was used for oxygen or air channel in cathode. Reactants inlet and outlet, seal ring slots and location holes were designed as well. Figure 3 is a schematic design of PBPs for the purpose of performance evaluation. Figure 3(a) shows the cathode side with serpentine flow field in which the reactant gas flows through GDL and catalyst layers by diffusion. Figure 3(b) is the anode side with interdigitated flow field in which solid arrows represent inlet hydrogen while dotted arrows stand for outlet hydrogen. The transport mechanisms of reactant gas are not only diffusion but also forced convection, which enhance the mass transfer and help to remove liquid water and heat.

PBPs, shown in Figure 4, were fabricated in-house. A stamping force of 80 tons loaded by Instron 1336 stamping machine was applied for about $20 \mathrm{~s}$ and the total cycle time for each bipolar plate was about $60 \mathrm{~s}$. Table 1 shows the parameters of PBPs. Aluminium and copper were machined by wire Electric Discharge Machining (EDM) and used as end plates and current collectors, respectively. Silicon gasket cut by laser was applied for sealing. Five-layer standard MEAs were purchased from FuelCellStore.com. Nafion ${ }^{\circledR} 112$ membrane with thickness of $0.05 \mathrm{~mm}$ and carbon clothes with thickness of $0.4 \mathrm{~mm}$ were assembled. Catalyst in anode and cathode is $0.5 \mathrm{mg} \mathrm{cm}$ and the projected active area is $4 \mathrm{~cm}^{2}$. MEAs were hot pressed into undulate shape at $135{ }^{\circ} \mathrm{C}$, $120 \mathrm{~kg} \mathrm{~cm}^{-2}$ for $90 \mathrm{~s}$ [19].

In order to evaluate the performance of the novel wavelike architecture stack, a single cell was assembled and tested in house, as shown in Figure 5. Humidification system (Fuel cell Technologies Inc.) was used to control flow rate and humidification of reactants. A Scribner 890 Fuel Cell Test Load Unit is available for various series of experiments such as scanning voltage, scanning current and dynamic load
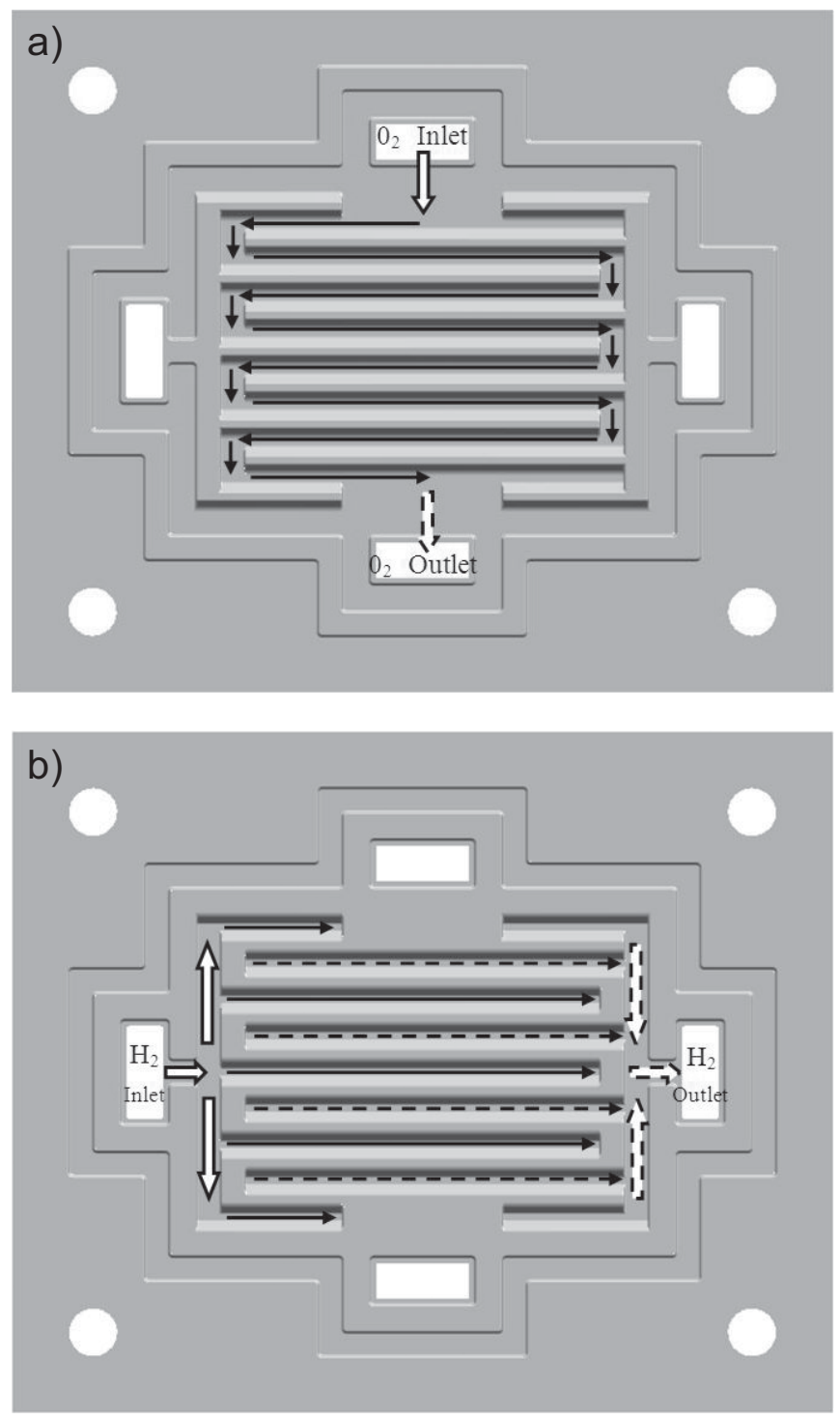

Fig. 3 Schematic design for stamped PBPs. (a) Cathode side of PBP with serpentine flow channel. (b) Anode side of PBP with interdigitated flow channel.

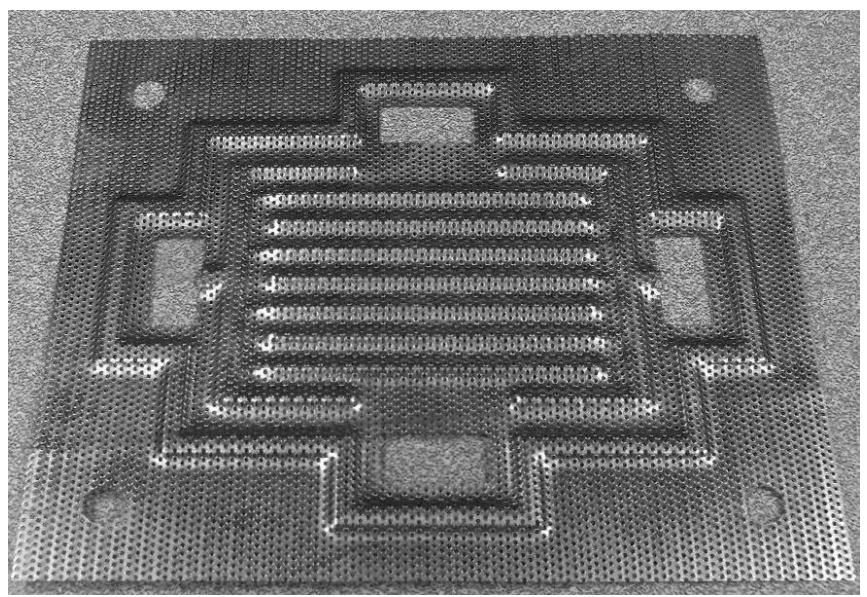

Fig. 4 PBP by stamping process. 


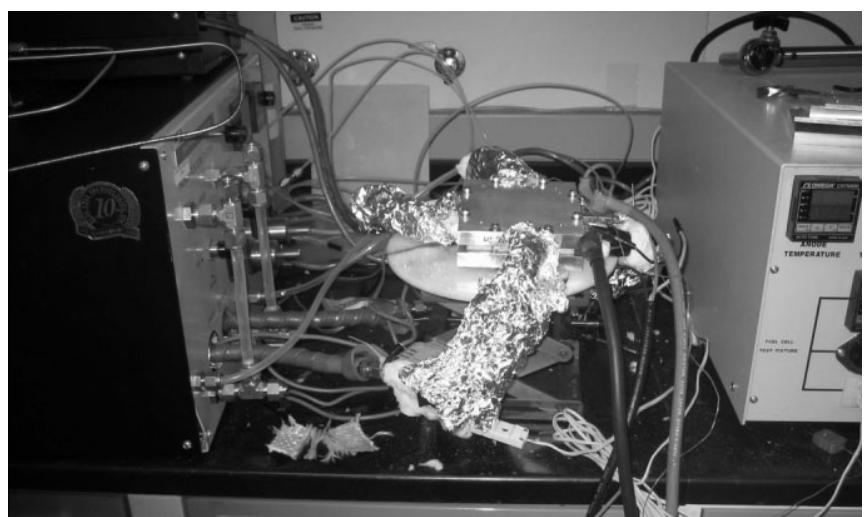

Fig. 5 Testing station for the novel wave-like architecture single cell.

response. The testing experiment was carried out under scanning current mode. Parameters for novel wave-like architecture single cell testing are shown in Table 2.

\section{Results and Discussion}

\subsection{Influence of Assembly Torque}

Polarisation curves and power density of the novel wavelike architecture single cell under different assembly torques at room temperature are shown in Figure 6. The cell peak power is improved from 360 to $420 \mathrm{~mW} \mathrm{~cm}^{-2}$ as assembly torque increases from 30 pound force inches (lbf.in) to $50 \mathrm{lbf}$.in. Nevertheless, it can be noted that there is a significant reduc- tion in the cell performance at the torque of $60 \mathrm{lbf}$.in and the peak power density drops to $370 \mathrm{~mW} \mathrm{~cm}^{-2}$, as shown in Figure 6 with circle symbols.

The main cause that the cell performance is affected by assembly torque is that the internal resistance is affected greatly by assembly torque. In order to eliminate the change in cell performance due to the change in internal resistance, the cell internal resistance free voltage $V_{\mathrm{iR} \text {-free }}$ is defined to be correct for cell internal resistance [20]. Figure 7 shows that cell iR-free voltage is almost the same under the assembly torque of 30, 40, 50 and $60 \mathrm{lbf}$.in. The internal resistance remains almost constant under different output voltages at the same assembly torque, whereas it changes greatly under different assembly torques. At the beginning, the internal resistance decreases from 290 to $260 \mathrm{~m} \Omega \mathrm{cm}^{-2}$ with the increase in assembly torque, but it increases quickly after 50 lbf.in and reaches $310 \mathrm{~m} \Omega \mathrm{cm}^{-2}$ at $60 \mathrm{lbf}$.in. This is quite different from the former researches [21-23] on the conventional architecture that the internal resistance decreases very quickly and then slowly as the clamping force increases. The possible reason for the difference is that two PBPs, which hold undulate MEAs, break away from MEAs due to the novel wave-like architecture when the assembly torque reaches $60 \mathrm{lbf}$.in. Therefore, the internal resistance and Ohmic losses increase dramatically; as a result, there is a significant drop in cell performance at $60 \mathrm{lbf}$.in. A conclusion can be drawn that there is an optimal assembly torque between 50 and $60 \mathrm{lbf}$.in for this single cell.

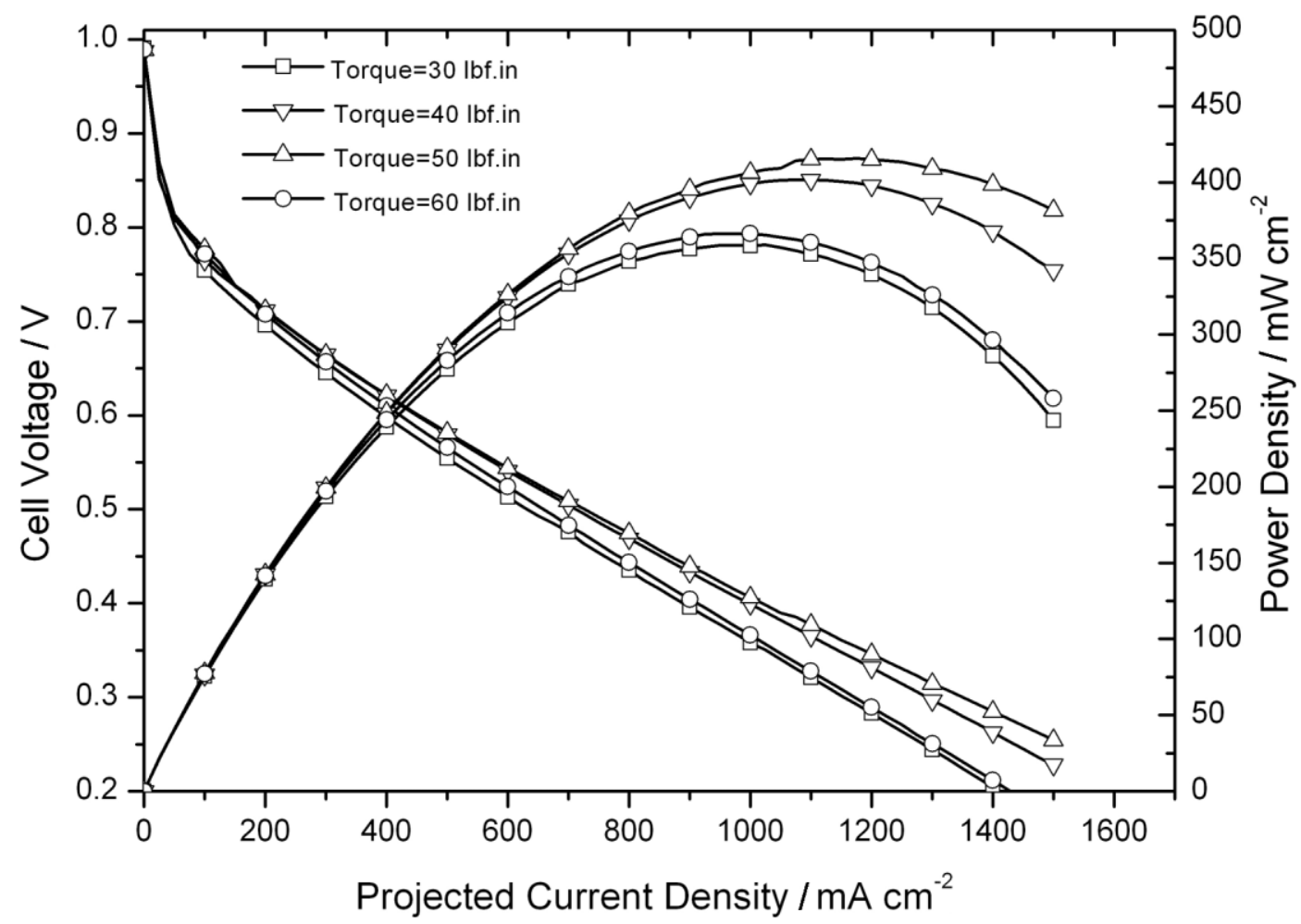

Fig. 6 Single cell performance under different assembly torque at room temperature. 


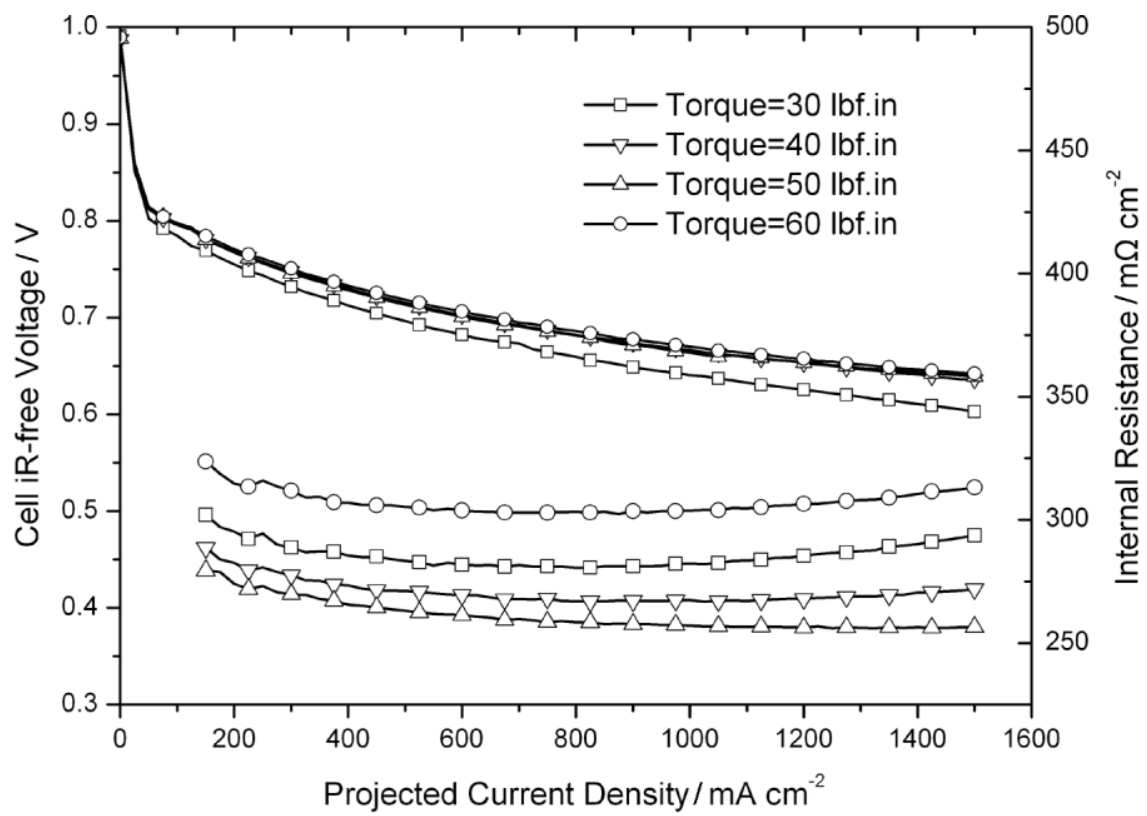

Fig. 7 Cell iR-free voltage and internal resistance under different assembly torque at room temperature.
Compared to the conventional plateand-frame architecture stack, significant improvement in volumetric power density and specific power is achieved in a novel wave-like architecture stack. As shown in Figure 9, the volumetric power density is $2,151.28 \mathrm{~W} \mathrm{~L}^{-1}$ at the output voltage of $0.6 \mathrm{~V}$, while the peak value is $2,715.94 \mathrm{~W} \mathrm{~L}^{-1}$. The specific power is $1,709.22 \mathrm{~W} \mathrm{~kg}^{-1}$ at the output voltage of $0.6 \mathrm{~V}$, while the peak value is $2,157.86 \mathrm{~W} \mathrm{~kg}^{-1}$. Although the specific power at $0.6 \mathrm{~V}$ is a little bit lower than DOE's 2010 technical target for stack, it should also be noted that the single cell for performance evaluation is just a case study and is not optimised either. Potential gains by using new MEAs, optimising flow channel and surface treatment of metal bipolar plate may be achieved so that this design may be used as a possible means to meet the DOE's target.

\subsection{Performance Evaluation for the Novel Design}

Baseline data were obtained by characterising the performance of a conventional planar single cell, consisting of graphite plates with single serpentine gas flow channel (channel depth $h=1.0 \mathrm{~mm}$, channel width $w=0.81 \mathrm{~mm}$, rib width $r=0.76 \mathrm{~mm}$, thickness of a bipolar plate $t=2.5 \mathrm{~mm}$ ) and with an active area of $4 \mathrm{~cm}^{2}$. The testing condition is exactly the same as novel wave-like architecture single cell.

Hentall et al. [3] presented a comparison result between stainless steel $316 \mathrm{~L}$ and graphite bipolar plate and showed that the performance of metallic bipolar plate is lower than graphite bipolar plate mainly due to its higher contact resistance. Nevertheless, the experimental results, shown in Figure 8, indicate that the actual polarisation characteristics of novel wave-like stack is comparative to conventional stack due to the great utilisation of the available volume of the fuel cell by undulate MEAs as mentioned before. The power density is higher than conventional stack when the output voltage is over $0.6 \mathrm{~V}$ while it is lower when the output voltage is below $0.6 \mathrm{~V}$. The reason that the cell voltage of novel architecture single cell decreases faster than the conventional planar single cell is that the contact resistance of stainless steel 316L is higher than graphite. From this perspective, there is an improvement in the polarisation performance of the novel wave-like architecture fuel cell stack.

\section{Conclusion}

In this study, a novel design of wave-like architecture for PEM fuel cell stack has been proposed. To evaluate its performance, a single cell was designed and fabricated in-house. Perforated sheet metal was stamped into wave-like bipolar plates and commercial MEAs was hot pressed into undulate shape. The effect of assembly torque was also obtained, which indicates the assembly torque of around $50 \mathrm{lbf}$.in can

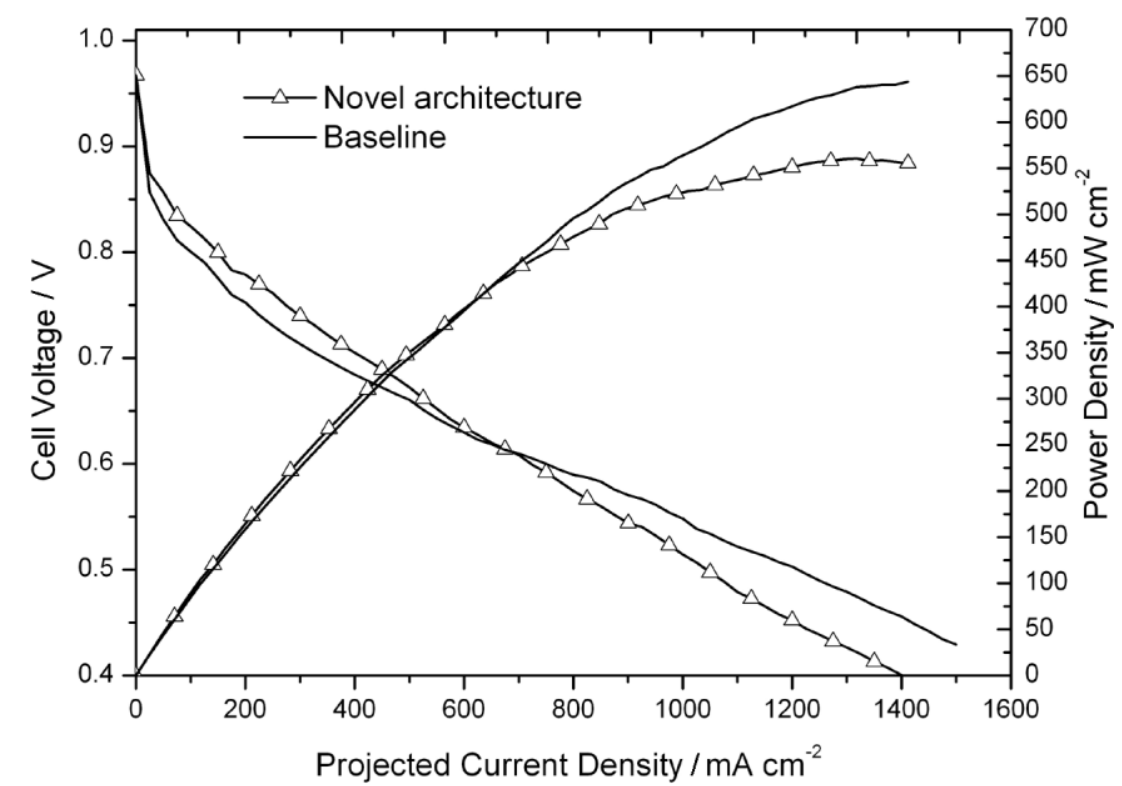

Fig. 8 Polarisation curve of novel wave-like architecture single cell at $80^{\circ} \mathrm{C}$ and comparison with conventional planar single cell. 

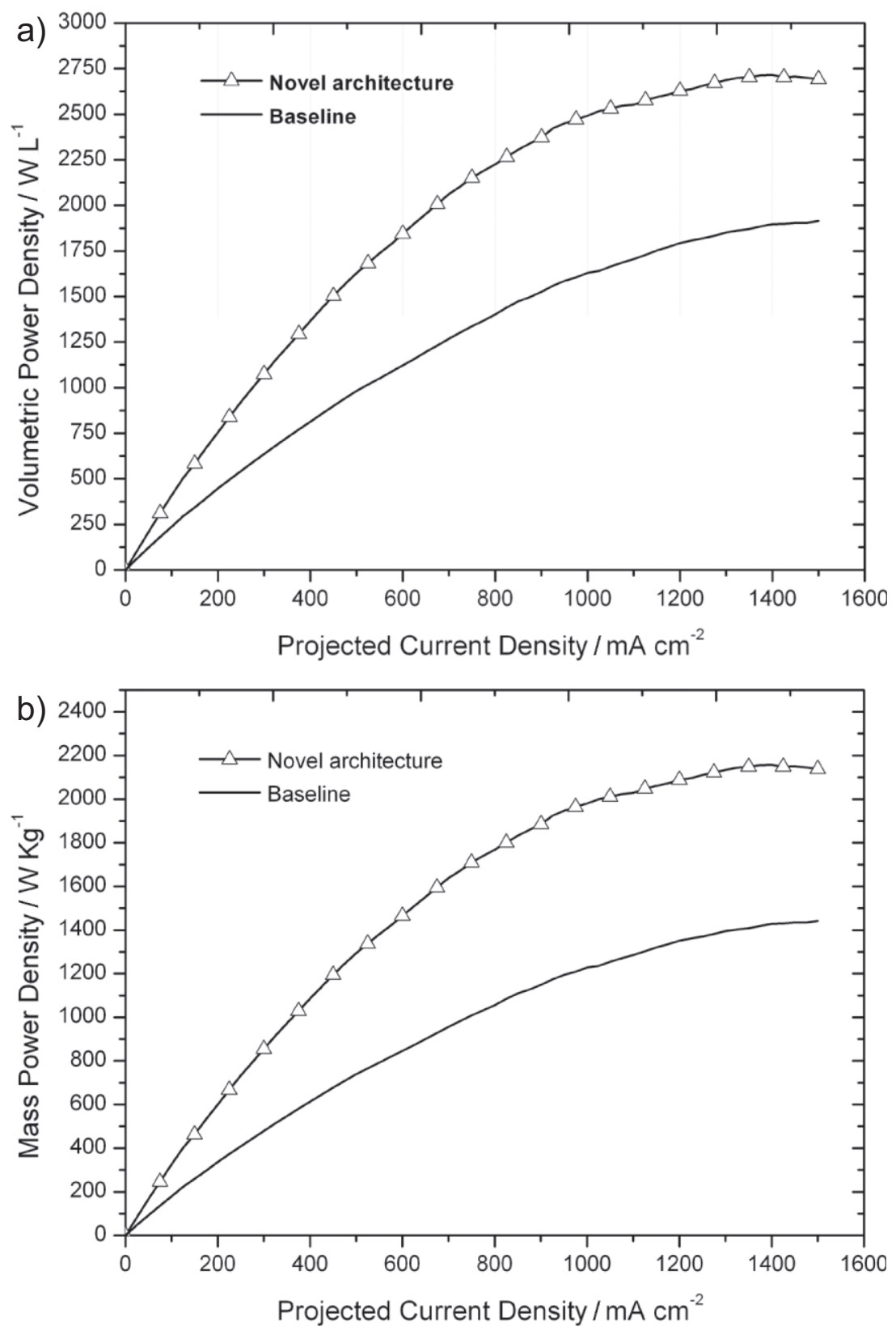

Fig. 9 Volumetric power density and specific power of novel wave-like architecture single cell and comparison with conventional planar single cell. (a) Volumetric power density. (b) Specific power.

bring an optimal performance for the single cell. Testing results and performance analysis show that the gains in volumetric power density and specific power in novel wave-like architecture stack are evident. This design may be used as a possible means to meet the DOE's 2010 technical target for stack. However, challenges in electrode connection, undulate MEAs handling and cooling channel remain the focus of ongoing efforts and future work.

\section{Acknowledgements}

This work was funded by National Natural Science Foundation of China (no. 50805092), Major International (Regional) Joint Research Project of NSFC (no. 50820125506) and Programme of Introducting Talents of Discipline to Universities (B06012). The authors would like to acknowledge and thank their financial supporters.

\section{Reference}

[1] EG\&G Technical Services, Inc., Fuel Cell Handbook, 7th Ed., US Department of Energy, 2004, pp. 1.

[2] G. Hoogers, Fuel Cell Technology Handbook, CRC Press, Boca Raton, FL 2003.

[3] P. L. Hentall, J. B. Lakeman, G. O. Mepsted, P. L. Adcock, J. M. Moore, J. Power Sources 1999, 80, 235.

[4] S. Gamburzev, A. J. Appleby, J. Power Sources 2002, 107, 5.

[5] US Department of Energy, Annual Progress Report-DOE Hydrogen Program, 2008, pp. 793. http://ww.hydrogen.energy.gov/pdfs/progress08/ v_a_1_ahluwalia.pdf

[6] M. C. Kimble, E.B. Anderson, K. D. Jayne, A. S. Woodman, "Micro-Tubular Fuel Cells," NASA Tech Briefs, Physical Science Inc. 2004, pp. 41.

[7] W. R. Merida, G. McLean, N. Djilali, J. Power Sources 2001, 102, 178.

[8] V. V. Nikam, R. G. Reddy, Int. J. Hydrogen Energy 2006, 31, 1863.

[9] J. K. Kuo, C. K. Chen, Int. J. Heat Mass Transfer 2007, 50, 4166.

[10] J. K. Kuo, C. K. Chen, J. Power Sources 2006, 162, 1122.

[11] W. Yoon, X. Huang, P. Fazzino, K. L. Reifsnider, M. A. Akkaoui, J. Power Sources 2008, 179, 265.

[12] Y. Wang, D. O. Northwood, J. Power Sources 2006, 163, 500.

[13] J. Wind, R. Spah, W. Kaiser, G. Bohm, J. Power Sources 2002, 105, 256.

[14] M. Li, S. Luo, C. Zeng, J. Shen, H. Lin, C. Cao, Corros. Sci. 2004, 46, 1369.

[15] H. Tawfik, Y. Hung, D. Mahajan, J. Power Sources 2007, 163, 755.

[16] H. Wang, M. A. Sweikart, J. A. Turner, J. Power Sources 2003, 115, 243.

[17] L. Wang, H. Liu, J. Power Sources 2004, 134, 185. 
[18] W. M. Yan, S. C. Mei, C. Y. Soong, Z. S. Liu, D. Song, J. Power Sources 2006, 160, 116.

[19] J. Zhang, G. P. Yin, Z. B. Wang, Q. Z. Lai, K. D. Cai, J. Power Sources 2007, 165, 73.

[20] Y. Song, J. M. Fenton, H. R. Kunz, L. J. Bonville, M. V. Williams, J. Electrochem. Soc. 2005, 152, A539.
[21] L. Zhang, Y. Liu, H. Song, S. Wang, Y. Zhou, S. J. Hu, J. Power Sources 2006, 162, 1165.

[22] V. Mishra, F. Yang, R. Pitchumani, ASME J. Fuel Cell Sci. Technol. 2004, 1, 2.

[23] Y. Zhou, G. Lin, A. J. Shih, S. J. Hu, J. Power Sources 2007, 163, 777. 